\title{
FLOW AROUND MODIFIED CIRCULAR CILYNDERS
}

\begin{abstract}
R. L. Ferreira
Faculdade de Engenharia de Ilha Solteira, FEIS-UNESP, Av. Brasil, 56, Cx.P. 31, CEP: 15385-000, Ilha Solteira, SP, Brasil ricardo@dem.feis.unesp.br

E. D. R. Vieira

Faculdade de Engenharia de Ilha Solteira, FEIS-UNESP, Av. Brasil, 56, Cx.P. 31, CEP: 15385-000, Ilha Solteira, SP, Brasil delrio@dem.feis.unesp.br

ABSTRACT

The flow around a circular cylinder has awaken the attention of different researchers since the historic Strouhal's work of 1878. Ever since, many experimental and numeric works have been carried out in order to determine the relationship between the vortex shedding frequency and the flow regime. Recently, a number of studies have been developed using several small modifications in circular cylinder. In this work a circular cylinder modified with a longitudinal concave notch, has been tested in order to determine the relationship between the non-dimensional vortex shedding frequency (Strouhal number) and the Reynolds number has been determined to Reynolds up to 600 . Additionally a modified circular cylinder with a longitudinal slit also has been tested in order to determine the Strouhal-Reynolds relationship in several attack angle configurations. The experiments have been carried out in a vertical low turbulence hydrodynamic tunnel with $146 \times 146 \times 500 \mathrm{~mm}$ of test section operating in continuous mode. Flow visualization by direct liquid dye injection has been utilized in order to produce vortex images. These images have been captured in still chemical photography for different Reynolds numbers. A hot-film probe has been adequately positioned in the vortex wake to determine the vortex shedding frequency and consequently the Strouhal number.
\end{abstract}

Keywords: Strouhal number, vortex shedding, modified cylinder, flow visualization, vortex wake.

\section{INTRODUCTION}

Vincez Strouhal, in 1878, carried out some historical experiments utilizing an Aeolian harp. This device consists of some wires of different diameters submitted to the natural wind producing wire vibrations and consequently a characteristic harmonic sound. In a traditional wire musical instrument the sound frequency is also dependent of the wire length, material and the stress applied to it. The wind blowing around the wire of the Aeolian harp produces the vortex-shedding phenomenon and Strouhal observed that the sound frequency was dependent only of the wire diameter and of the wind velocity. The vortex shedding excites the wires to a vibration in the same frequency of vortex shedding, producing a sound that is amplified utilizing a resonance apparatus. Utilizing a Koenig's sonometer, Strouhal determined the sound frequency whereas the wind velocity was most likely evaluated using a Pitot tube. It is important to observe that the data obtained by Strouhal is very close to the modern data obtained by Anatol Roshko in 1953, utilizing a wind tunnel and hot-wire anemometry. More details about the historical Strouhal's experiments are obtained in Zdravkovich (1996 and 1997).

Since Strouhal's works, many other researchers have been dedicated to the study of the problem of the flow around bluff-bodies with different geometries. Most of those works were carried out on cylinders with circular, square and rectangular crosssection, but the flow around circular cylinders remains the principal subject of research. The study of vortex shedding in the wake of a circular cylinder in relative low Reynolds number $(\mathrm{Re})$ has been the subject of several experimental and numerical analysis. However, there are relatively few works on flow around circular cylinders exhibiting some small but significant modifications in geometry, either by the addition of a bar or splitter plate, for example, or by carving a notch or a slit along the surface of the cylinder. Since circular cylinders in such a way modified and submitted to a flow field find an important place in quite a number of modern-life applications, it seems, from an engineering viewpoint, very useful to understand the extent of their effect on the vortex shedding frequency. On the other hand, this is an important research field because of the insight it provides into the basic vortex-shedding mechanism.

Some experiments have been proposed employing tabs or splitter plates mounted on the downstream side of the cylinder. The principal function of these tabs is to reduce the communication of pressure fluctuations across the cylinder, which can reduce the value of the vortex shedding frequency. In fact, if an interference element is adequately positioned in the vortex wake, significant changes can be produced in the pressure and drag coefficients and 
consequently in the non-dimensional vortex shedding frequency, the Strouhal number $(\mathrm{St})$.

Nigim \& Batill (1997) have proposed small modifications in the cylinder surface in order to promote Strouhal alterations. With a circular cylinder of $44.5 \mathrm{~mm}$ of diameter and a wire of $4 \mathrm{~mm}$ of diameter glued longitudinally along the cylinder surface, they noticed that the vortex-shedding frequency ( $f$ ) is a function of the surface perturbation angle.

Roshko (1955) has employed splitter-plates downstream circular cylinders, in order to show a possible reduction in the Strouhal number. Also Igarashi (1984) using circular cylinder with a short length splitter-plate and a gap from the cylinder for Reynolds number of 22000 found a noticeable Strouhal interference. More interestingly, Igarashi's results exhibit a jump in Strouhal number for an increasing variation of the gap between the splitterplate and the cylinder. Splitter plates downstream bluff-bodies with different geometries have been studied in order to promote a stable StrouhalReynolds relationship, much desirable in the case of vortex flowmeters, as explained by Olsen \& Rajagopalan (2000).

According to Nakamura (1996), in Reynolds ranging from 1600 up to 5300, a strong reduction (half the value for the non-modified regular circular cylinder) in the Strouhal number is achieved utilizing slender splitter plates of several lengths (up to about six times the diameter).

If an interference element placed in the wake impairs a pressure fluctuation communication and consequently a reduction in the Strouhal number value, the opposite concept may also be true, i.e., if an interference element existing in the circular cylinder facilitates the pressure communication across the cylinder, we should observe an increment in the non-dimensional vortex shedding frequency.

In the present experimental work, circular cylinders with a longitudinal notch have been tested and the results have been compared with a regular circular cylinder the same diameter. Additionally, a circular cylinder modified by an axial slit has been tested for different attack angles. The nondimensional vortex shedding frequency (St) to the Reynolds number relationship was evaluated for Reynolds (Re) up to 600.

\section{EXPERIMENTAL CONDITIONS}

In this work, an experimental effort to measure the Strouhal (Sr) - Reynolds (Re) relationship has been carried out. The test bodies, the vertical hydrodynamic tunnel and the apparatus to measure the vortex shedding frequency and to capture the flow images are described in detail in the following subsections.

\section{TEST BODIES}

The modified circular cylinders each with a different 3-mm deep longitudinal notch have been submitted to a flow field with a homogeneous velocity profile and low relative turbulence level. The cylinders have been adequately positioned ortogonally in relation of the free flow and the longitudinal notch positioned coincidentally with the stagnation point in the front of the cylinder. Three modified cylinders each one with $8 \mathrm{~mm}$ of nominal diameter (D) have been utilized in the experiments and the results have been compared with the results obtained by a nonmodified circular cylinder with the same diameter. Figure (1) sketches the geometry of these cylinders tested showing the concave notch turned upstream (first test configuration). All cylinders have been made in polished aeronautical aluminum.

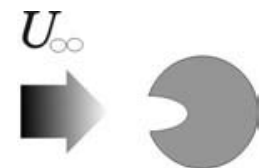

(a)

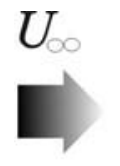

(b)

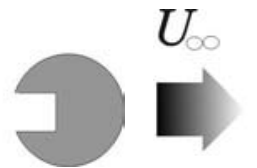

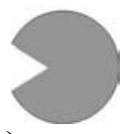

(c)
Figure 1. Modified circular cylinders with longitudinal notch and their test configurations utilized.

In a second phase, a circular cylinder modified by a longitudinal slit is adequately positioned in the test section of a hydrodynamic tunnel under several attack angles in order to determine the StrouhalReynolds relationship for Reynolds numbers up to 600 . Figure (2) shows the geometry of this modified circular cylinder tested, the slit gap dimension and the attack angle $(\alpha)$. Figure (2) also shows a hot-film probe positioned in the vortex wake.

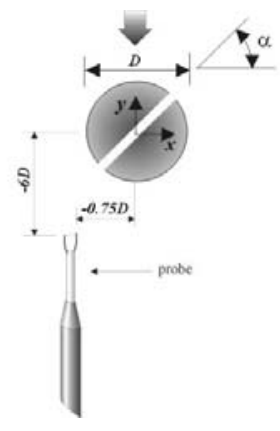

Figure 2. Modified circular cylinder with axial slit and the hot-film probe position (no scale).

\section{HYDRODYNAMIC TUNNEL}

All experiments have been carried out in a verticallow-turbulence water tunnel, depicted in Figure (3). This apparatus, recently modified and described briefly in the work of Gonçalves \& Vieira (1999), permits operation in continuous or in blow-down mode. In blow-down operation mode it is possible to obtain a relative low turbulence level (less than $0,10 \%$ in the test section centerline), but the continuous decreasing of the flow velocity offers a serious limitation for the tests and this operation mode is utilized only to in short-time runs. All tests described in this work have been carried through in continuous operation mode, which permits a long time of operation in a constant velocity. The vertical test section has $146 \times 146 \times 500 \mathrm{~mm}$ of dimensions. The test section has a square cross-section with chamfered corners and a cross-section area with $0.0186 \mathrm{~m}^{2}$ and permits to shelter cylinders of $8 \mathrm{~mm}$ of diameter 
provoking a blockage ratio of less than $6.6 \%$. An extensive description of water tunnel facility and flow visualization hardware, including recent modifications and instrumentation, is available in Lindquist (2000) and Gonçalves (2001). The relative turbulence level - measured in percent - and the mean velocity profile, both measured in the centerline of the test section, and are showed in the Figure (4).

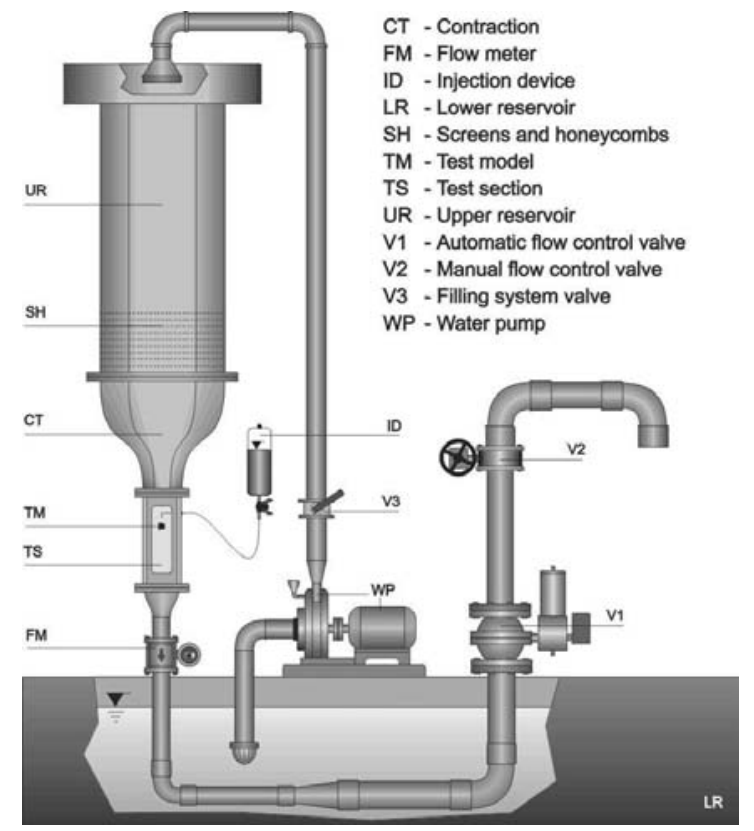

Figure 3. Low turbulence vertical hydrodynamic tunnel.

The Reynolds Number $(R e)$ is a nondimensional parameter defined by:

$$
\operatorname{Re}=\frac{\rho V D}{\mu},
$$

where $(\rho)$ is the fluid density, $(D)$ is the characteristic diameter of the cylinder, $(V)$ is non-perturbed flow velocity and $(\mu)$ is the viscosity.

The Strouhal number $(S t)$, is also utilized:

$$
S t=\frac{f D}{V},
$$

where $(f)$ is the vortex shedding frequency.

The non-perturbed flow velocity upstream the test model has been obtained using a Yokogawa electromagnetic flow meter mounted downstream the test section. Measuring the flow rate and knowing the cross-section area in the test section it is possible to obtain the free velocity. An estimate of the errors associated to free stream velocity amounts to less than about $4 \%$, when compared with data obtained by hot film anemometer.

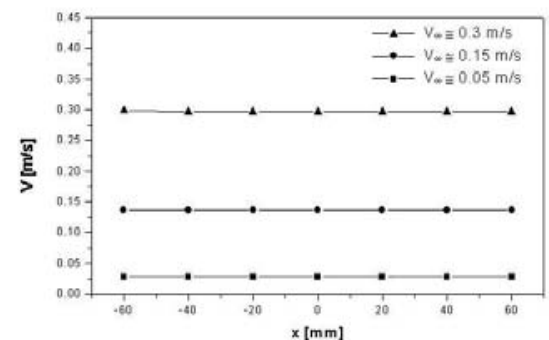

(a)

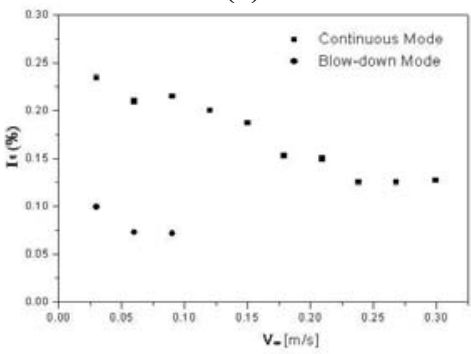

(b)

Figure 4. (a) Mean velocity profile and (b) relative turbulence level $\left(\mathrm{I}_{\mathrm{t}}\right)$ inside the test section.

\section{IMAGE CAPTURE}

The still images have been captured utilizing a SLR (single lens reflex) Nikon F4s camera on $24 \times 36 \mathrm{~mm}$ negative film, equipped with two high luminosity objectives: a Nikor macro $60 \mathrm{~mm} / \mathrm{f} .1: 2.8$ and a medical macro $120 \mathrm{~mm}$. The principal opposition to the use of SLR cameras in scientific works is the vibration caused by the mirror in the shooting moment that can cause camera trepidation and generation of sharpless images. But Nikon F4 cameras have a mechanism that permits keeping elevated and locked the mirror, eliminating all vibrations caused by the mirror movement. In addition, this camera has an electric control curtain shoot with a very small trepidation, making it the camera adequate to laboratory applications.

The photos have been developed using Kodak TMax 400 (ISO 400) black and white (B\&W) negative films. This B\&W chemical photographic pellicle incorporates the modern T-grain technology who permits high speed and fine grain allied to a sharp high contrast and good definition of gray tons, producing a higher overall image quality. Additionally, TMax roll film permits wide variations in contrast and velocity controlled by developing process. The films have been developed using Kodak Tmax $R S$ developer to obtain a fine grain and image details under a controlled contrast. The prints have been executed in Kodabromide grade 4, a smooth paper with high contrast, the indicated paper for technical photography. Images have been digitized utilizing a flat bed scanner in 8 bits of grayscale (only 256 tones of gray).

The direct injection of liquid dye upstream the bluff-body test was utilized for image generation. Dye injection is a very useful technique and by means of a long hypodermic needle (E.D. $=0.5 \mathrm{~mm}$ ), a black opaque liquid dye is injected in the free flow, permitting the visualization of streaklines. A second flow visualization method was utilized in this work, named dye wash technique. Large amount of a dense black dye is injected, through of a needle rake, close of the test model, enough to tint the entire flow field. Suddenly, the dye injection is stopped; the 
hypodermic needle rake is taken off the flow, in order to minimize flow perturbations. The clean water flow washes the entire flow field, except in the cylinder wake, since in this region the flow speed is significantly smaller than in other regions. This procedure allows, during some seconds, for the wake downstream the cylinder to be watched. Dye wash technique is strongly recommended for visualization of zone near the leeward face of the solid obstacle.

\section{STROUHAL NUMBER DETERMINATION}

In the technical literature the nondimensional vortex shedding frequency is determined in several ways, as shown in the comprehensive review by Gonçalves \& Vieira (1999). The use of direct flow visualization in order to determine the Strouhal number is a simple, implementation-easy and cheap technique. Unfortunately, since automatic vortex image recognition is unavailable, the visual observation of each individual vortex is a cumbersome and time-consuming task. Another restriction to the use of direct flow visualization for vortex frequency determination is noted by Lindquist et al. (1998). They have shown that, in many cases, for several bluff-body geometries there are two dominant frequencies for the same Reynolds number, but flow visualization detects only a mean value of these two frequencies. In this case, the precise frequency determination should be carried out utilizing other techniques. In order to determine the Strouhal number, many researchers utilize the velocity acquisition data downstream the cylinder. A velocity probe is inserted in the vortex wake and the temporal variation of velocity is captured. Utilizing an FFT (Fast Fourier Transform) it is possible to determine the vortex shedding frequency. The velocity signal can be captured utilizing several methods, notably hot-wire and laser anemometry. Hot-wire is a recognized technique utilized by several research laboratories. In this work, a commercial Dantec 55R11 hot-film probe was inserted adequately downstream the cylinder with help of the flow visualization, as depicted in Figure (2), in order to capture the temporal velocity fluctuations, and the signal was processed through FFT to determine the vortex frequency. The adequate probe positioning in the vortex center permits to obtain a high signal to noise ratio (SNR) and a sharp value of the dominant vortex frequency. The use of two techniques, flow visualization allied to hot-film anemometry, shows promising results. To assess the combination of visualization and hot-wire anemometry techniques, see the paper of Freymuth et al. (1983) in which a review of past efforts in this area is presented. The uncertainty analysis attributed to frequency measurements, in according to Moffat (1982), is less than $5 \%$.

\section{RESULTS FOR CIRCULAR CYLINDERS WITH CONCAVE NOTCH}

The present results, relatively to the flow velocity captured in the vortex wake are expressed in terms of anemometer output voltage $\left(\mathrm{E}_{0}\right)$. Figure (5) depicts, for Reynolds number value of 100 , the flow velocity (without calibration) downstream a non-modified circular cylinder (CC) comparative to the modified circular cylinders with a semi-circular notch $(\mathrm{CN})$, square notch $(\mathrm{SN})$ and triangular $\operatorname{notch}(\mathrm{TN})$.

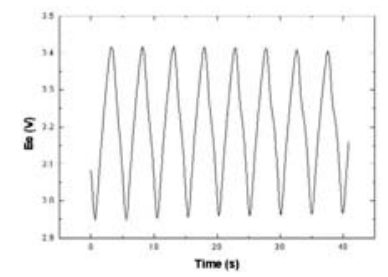

(a) $\mathrm{CC}$

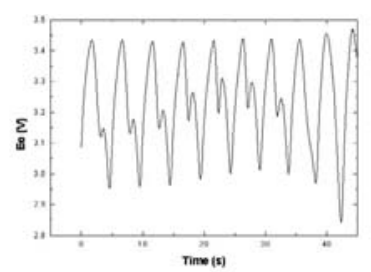

(c) $\mathrm{SN}$

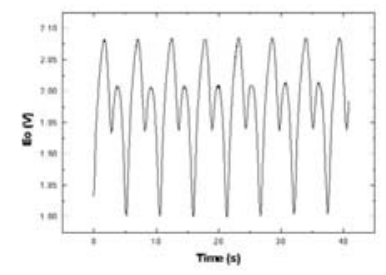

(b) $\mathrm{CN}$

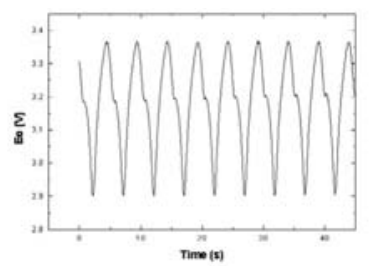

(d) $\mathrm{TN}$
Figure 5. Typical anemometer output signal $\left(\mathrm{E}_{0}\right)$ for nonmodified (CC) and modified cylinders, for $\mathrm{Re}=100$.

Figure (6) shows the Strouhal number behavior as function of the Reynolds number for the non-modified cylinder and the three modified cylinders. Figure (7) exhibits images of the visualized flow on the circular cylinder without modification (CC) and of the cylinder modified with a semi-circular notch $(\mathrm{CN})$. The vortex wake images have been also recorded in videotape; the analysis of the videotape images comparing the wake visualized permits to observe negligible differences in the vortex wake of nonmodified and modified cylinders. In the images showed in Figure (7) the hot-film probe and support downstream the cylinder immersed in the vortex wake can be seen.

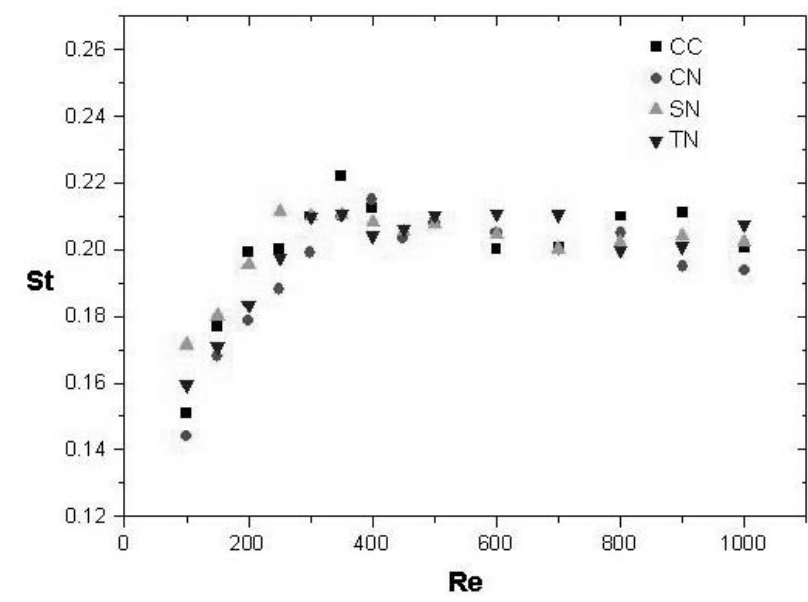

Figure 6. Strouhal number (St) vs Reynolds number (Re). 


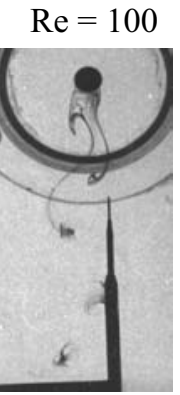

(a) $\mathrm{CC}$

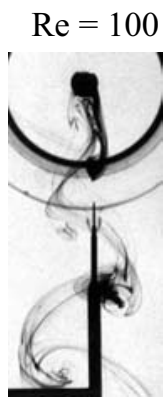

(b) $\mathrm{CN}$

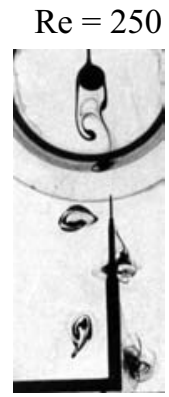

(c) $\mathrm{CC}$

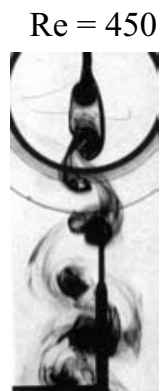

(d) $\mathrm{CN}$

Figure 7. Vortex wake images of the circular cylinder (CC) and the modified cylinder with a semi-circular notch $(\mathrm{CN})$.

\section{RESULTS FOR CIRCULAR CYLINDER WITH A AXIAL SLIT MODIFICATION}

The modified circular cylinder tested has a slit with a gap of $1.5 \mathrm{~mm}$. The cylinder is turned from $(\alpha)$ equal to 0 up to $90^{\circ}$ while the Reynolds number ranged from 100 to 600 . Figure (8) pictures the Strouhal number behavior in function attack angle $(\alpha)$ configuration parameterized in relation to Reynolds number.

Figure (9) pictures the Strouhal behavior obtained for three different attack angles $(\alpha=0,45$ and $90^{\circ}$ ) parameterized in Reynolds obtained in this present work, with a slender ratio of 18:1, compared with the results obtained por Olsen \& Rajagopalan (2000). Olsen \& Rajagopalan (2000) have utilized an open-circuit wind tunnel $(320 \times 320 \mathrm{~mm}$ of test section) with low free-stream turbulence $(<0.1 \%)$. The cylinder diameter utilized is only $3 \mathrm{~mm}$ provoking a slender ratio of approximately 107:1.
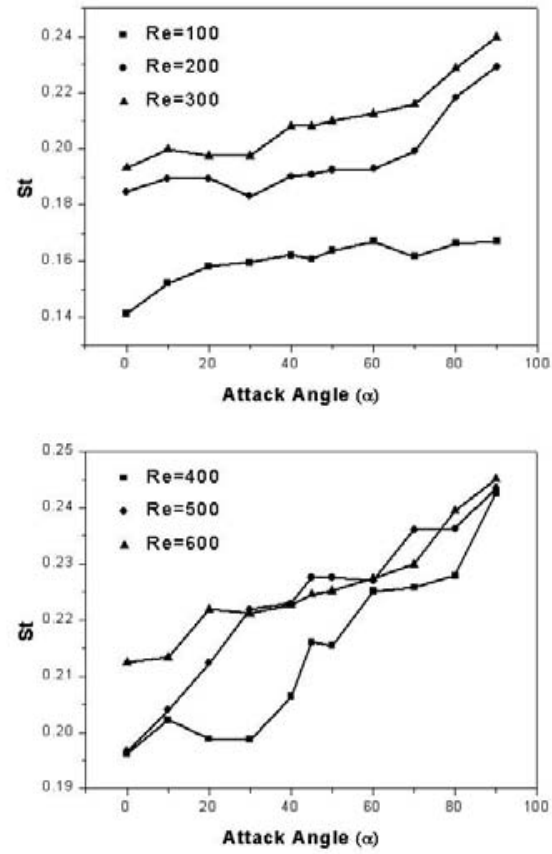

Figure 8. Strouhal number as function of attack angle parameterized in Reynolds.

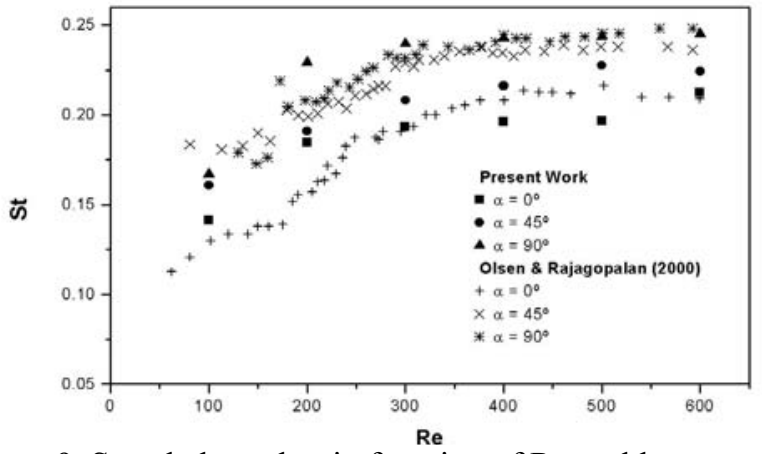

Figure 9. Strouhal number in function of Reynolds parameterized in attack angle $(\alpha)$.

The output voltage of the anemometer (noncalibrated signal) $\left(\mathrm{E}_{0}\right)$ recorded through a $\mathrm{A} / \mathrm{D}$ board, for the axial slit modified circular cylinder is showed in the Figure (10) for attack angle $\alpha=45^{\circ}$.

Figure (11) shows the FFT signal analysis for Reynolds equal to 600 in three different attack angle configurations $\left(\alpha=0,45\right.$ and $\left.90^{\circ}\right)$.
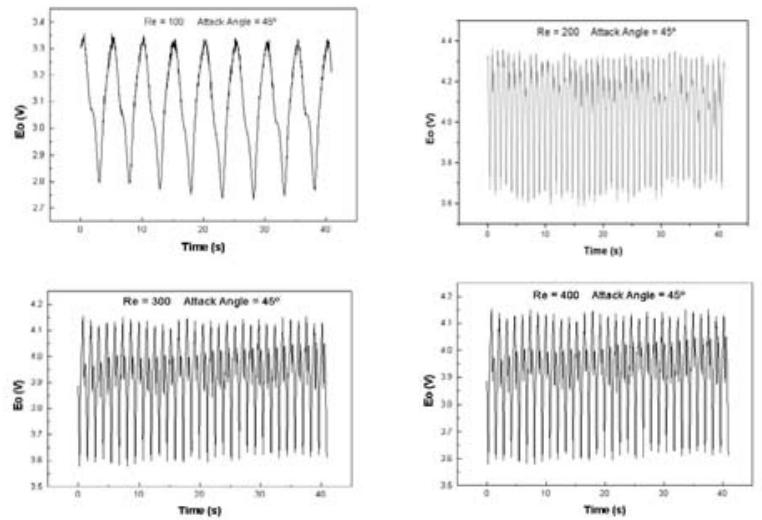

Figure 10. Output voltage of the anemometer (E) for a slit modified cylinder with $\alpha=45^{\circ}$.

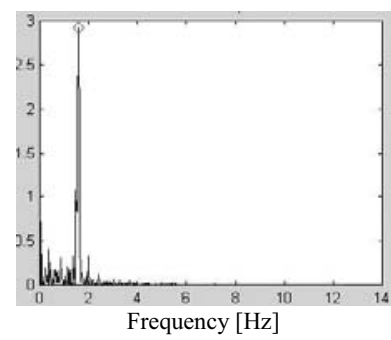

(a) $\alpha=0^{\circ}$

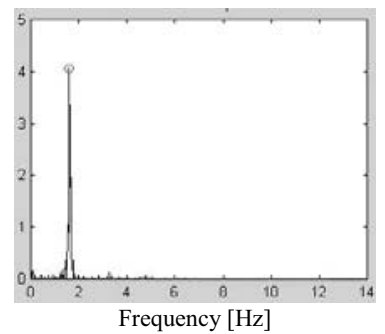

(b) $\alpha=45^{\circ}$

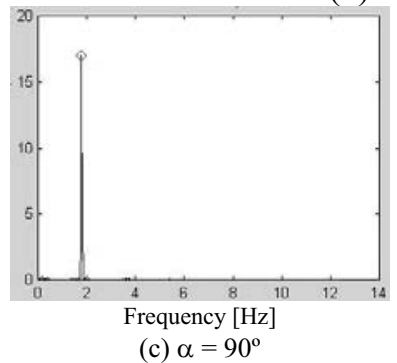

Figure 11. Relative spectral density in function of the frequency for a slit modified cylinder with $\alpha=0,45$ and $90^{\circ}$.

Figure (12) shows the visualized flow image pictures for three Reynolds number $(\operatorname{Re} \approx 50,100$ and 200) 
to the modified cylinder with an axial slit with zerodegree attack angle $(\alpha)$.
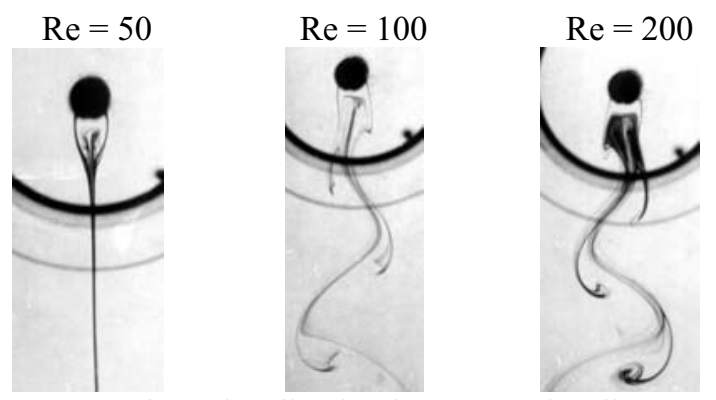

Figure 12. Flow visualization images of the slit modified cylinder wake with $\alpha=0^{\circ}$.

\section{CONCLUSIONS}

Experiments were conducted on modified circular cylinders with concave notch and axial slit to investigate the vortex shedding characteristics. Three modified circular cylinder with concave notch have been tested (for $\alpha$ equal to zero degree) and no significant variations on the Strouhal number can be noted in the Reynolds range tested. However, the axial slit modified cylinder shows a strong vortex shedding frequency variation for the three attack angle tested. The major vortex shedding frequency alteration is observed in $\alpha=90^{\circ}$ (the slit normal to the flow) possibility due to the pressure communication.

The flow structures showed in the wake of circular cylinders modified with concave notch are very similar to those from the regular circular cylinder.

But, the cylinder modified with an axial slit shows strong flow structure alterations relatively to the unmodified circular cylinder. For example, in the Figure (12a) the permanent vortex bubble shows a significant difference when compared with the permanent vortex bubble produced by a circular cylinder. In the same way, the non-permanent vortex bubble downstream the modified cylinder Figure $(12 b, c)$ shows alterations when compared with the bubble produced by a circular cylinder without modifications.

The hot-film traces obtained in $y / D=6$ show that the presence of the slit normal to the flow $\left(\alpha=90^{\circ}\right)$ increases the amplitude and enforces the periodicity (or reduces the randomness) of the vortex shedding, according to Figure (11).

No attempt has been made to modify the end conditions, e.g. by using endplates to force parallel vortex shedding modes.

Finally, a combination of the two techniques - flow visualization and hot-film anemometry - with each technique strongly reinforcing and complementing each other, was utilized with success in the present work.

\section{ACKNOWLEDGEMENT}

We gratefully acknowledge the financial support provided by FAPESP, Fundunesp and PROPP-Unesp. The authors express too their sincere tanks to Dr. E. R. Woiski, for his assistance in the reading of the manuscripts.

\section{REFERENCES}

Gonçalves, H.C. and Vieira, E.D.R., 1999, "Strouhal Number Determination for Several Regular Polygon Cylinders for Reynolds Number up to 600 ", Proceedings of the COBEM 99 - XV Brazilian Congress of Mechanical Engineering, Águas de Lindóia.

Gonçalves, H.C., 2001， "Determinação Experimental da Freqüência de Emissão de Vórtices de Corpos Rombudos", Dissertação de mestrado, Unesp - Ilha Solteira.

Igarashi, T, 1984, "Correlation Between Heat Transfer and fluctuating Pressure in Separate Region of a Circular cylinder", International Journal of Heat and Mass Transfer, Vol. 27, pp. 927-937.

Lindquist, C., Mansur, S.S. and Vieira, E.D.R., 1998, "Estudo Experimental do Escoamento ao Redor de Cilindros Retangulares: Uma aplicação aos Trocadores de Calor Compactos", Proceedings of the ENCIT 98 - VII Brazilian Congress of Thermal Engineering and Sciences, Vol. 2, pp.557-561.

Lindquist, C., 2000, "Estudo Experimental do Escoamento ao Redor de Cilindros de Base Quadrada e Retangular", Dissertação de mestrado, Unesp - Ilha Solteira.
Moffat, R.J., 1982, "Contributions to the theory of singlesample uncertainty analysis", Journal of Fluids Engineering, Vol.104, pp.250-260.

Nakamura, Y., (1996), "Vortex Shedding from Bluff bodies with Splitter Plates", Journal of Fluids and Structures, Vol. 10, pp. 147-158.

Nigim, H. H. and Batill, S. M., 1997, "Flow About Cylinders with Surface Perturbations", Journal of fluids and Structures, Vol. 11, pp. 893-907.

Olsen, J.F. and Rajagopalan, S., 2000, "Vortex Shedding Behind Modified Circular Cylinders", Journal of Wind Engineering and Industrial Aerodynamics, Vol.86, pp.55-63.

Roshko, A, 1953, "On the development of Turbulent Wakes from Vortex Streets", NACA Technical Reports TN 2913.

Roshko, A, 1955, "On the Wake and Drag of Bluff Bodies", Journal of Aeronautical Sciences, Vol.22, pp.124132.

Zdravkovich, M. M., 1996, “Different Modes of Vortex Shedding: An Overview", Journal of fluids and Structures, Vol. 10, pp. 427-437.

Zdravkovich, M. M., 1997, "Flow Around Circular Cylinders - Vol. 1: Fundamentals", Oxford Science Publications, Oxford. 